Annual Review of Applied Linguistics (1999) 19, 105-132. Printed in the USA. Copyright ${ }^{\odot} 1999$ Cambridge University Press 0267-1905/99 \$9.50

\title{
SOCIOLINGUISTIC APPROACHES TO SLA
}

\author{
Richard Young
}

\section{$\underline{\text { INTRODUCTION }}$}

The study of second language acquisition involves understanding what bilinguals know about their second language and how they acquire and use it. ${ }^{1}$ Because acquisition and use occur in a social context, it is important for secondlanguage acquisition researchers to understand the ways in which social context and the acquisition and use of a second language are related. In recent years, our understanding of language as a social phenomenon has increased greatly. In a recent survey of sociolinguistics and language teaching, McKay and Hornberger (1996) divide the field into four related areas: 1) studies of language and society-how large-scale social and political issues affect language use in a particular society, 2) studies of language variation-how the "same" language varies from speaker to speaker, from place to place, and from situation to situation, 3) studies of language and interaction-how language is used in face-toface communication, and 4) studies of language and culture-how particular cultures privilege some kinds of language over others.

Sociolinguistic approaches to SLA have been very popular in recent years and to survey all the work published in the past five years would be to risk losing focus in such a short article as this. Fortunately, there are other articles in this and recent volumes of $A R A L$ that have surveyed other parts of this broad field, and so I have chosen to omit all but passing reference to four important areas of sociolinguistic research in SLA: pragmatics, classroom second and foreign language learning, literacy, and multilingualism. Pragmatics is arguably one of the liveliest areas of current sociolinguistic research in SLA, but it is reviewed in a separate article in this volume. A second area of intense interest for researchers and educators is the socialization of second and foreign language learners in schools, but instructed SLA is also the topic of another article in this volume. Third, research into the social contexts of literacy in a second language was reviewed in $A R A L$ volume 12 (1992) and so I will limit the present review to 
spoken language. And finally, multilingualism was also the subject of a recent $A R A L$ volume-volume 17 in 1997-and will not be covered here.

What remains to be reviewed in this article falls within the second and third areas of McKay and Hornberger's (1996) survey: language variation and face-to-face communication. Some of the questions that interest SLA researchers studying these areas include the following: Why do bilinguals speak differently in different situations and with different people? What are the causes of miscommunication in conversations between people from different cultures? How do patterns of conversation differ in different languages and do bilinguals transfer conversational patterns from their first language into a second language? And how does speaking a second language influence an individual's sense of social identity? In this survey, I will review recent answers that SLA researchers have given to those questions. In what follows, I will first discuss two complementary traditions in the study of social context and show how a researcher's theory of context influences the research methodologies that he or she adopts. I will then go on to review the substantive findings of sociolinguistic researchers in four main areas of second language acquisition and use: interlanguage variation, cross-cultural communication, conversational phenomena, and social identity. I will conclude with a review of three sociolinguistic theories of SLA that have been put forward to explain some of these phenomena.

\section{TRADITIONS IN THE STUDY OF SOCIAL CONTEXT}

SLA researchers have by and large adopted the methods of mainstream sociolinguists in order to answer questions such as those above, and two very different approaches appear in their research according to the individual researcher's view of social context. Such a division in interpreting context is understandable: Context is an easy word to use but a very difficult concept to define. In their introduction to a collection of essays on context written by anthropologists and sociologists, Goodwin and Duranti (1992) put the general notion clearly: "The notion of context...involves a fundamental juxtaposition of two entities: 1) a focal event, and 2) a field of action within which that event is embedded" (p. 3). For sociolinguists, the focal event is language and the field of action is whatever else the researcher is interested in. Researchers' interests differ, of course, and Goodwin and Duranti (1992) review eight different traditions in the analysis of social context. For the purposes of this review, I will note just one important way in which traditions differ. On the one hand, in most research in language variation and interactional sociolinguistics, context is taken as a given and is described in terms of categories that exist in advance of the focal instance of language use and endure throughout it. In this view, the setting of language use, as well as participants' cultural background, first language, second-language proficiency, gender, social status, and other social categories can be described independently of language use. On the other hand, the predominant approach taken by ethnomethodologists and conversational analysts studying face-to-face communication is that pre-existing social categories are relevant in understanding a 
focal instance of language use only to the extent to which participants orient themselves to those categories in interaction. In this contrasting view, context is emergent and dynamic, and participants do not bring categories with them to an interaction but rather they are negotiated through interaction. Sometimes, these contrasting views of context-as given or emergent-lead to quite different interpretations of interaction. Ehrlich (1997), for instance, argues that the ease with which researchers have taken participants' gender as a given in interaction has masked more relevant contextual factors, and Siegal (1996) describes how a Western woman in Japan negotiates her own identity by rejecting the linguistic and interactional features associated with feminine gender in Japanese society.

\section{METHODS OF INOUIRY}

These contrasting theories of context have given rise to very different methods of inquiry. In the tradition of studies of interlanguage variation, researchers have correlated features of context-treated as independent variables-with variation in a particular linguistic form. Adamson, et al. (1996), Bayley (1994; 1996), Preston (1996), Regan (1996), Tarone and Liu (1995), and Young (1996) are studies in this tradition. These researchers subscribe to what Young and Bayley (1996) have called the principle of quantitative modeling:

This means that we can examine closely the forms that a linguistic variable takes, and note what features of the context co-occur with these forms. By context, we mean the surrounding linguistic environment and the social phenomena which co-occur with a given variable form. With a large enough set of data, we are able to make statements about the likelihood of co-occurrence of a variable form and any one of the contextual features in which we are interested. These statements express in quantitative terms the strength of association between a contextual feature and the linguistic variable (1996:253).

In contrast, researchers who consider context as emergent and dynamic eschew quantification in favor of rich and detailed description of naturally occurring spoken interactions. Representative of this approach is Markee (1994), who describes what he calls a hermeneutic approach to SLA as follows:

"Hermeneutics (meaning 'the art of interpretation') assumes that multiple realities exist and that human events can be interpreted only according to their outcomes. In terms of research methodology, .. a naturalistic, qualitative methodology is associated with the hermeneutic tradition" (1994:90). The hermeneutic tradition has emerged as the dominant tradition in sociolinguistic research in SLA over the past five years. The most fully contextualized of these studies is the literary genre of learner autobiographies (Davidson 1993, Hoffman 1989, Kaplan 1993, Liu 1984, Mori 1997, Rodriguez 1982, Watson 1995) in which the authors reflect at length on their lifelong experiences as second language learners. Language learners' diaries and case studies form a similar genre-the latter are just as richly contextualized as learner autobiographies but generally less available because they 
are shorter than autobiographies and rarely published on their own. Ehrman (1996), Pickett (1978), Schumann (1997), and Stevick (1989) contain extensive quotations from language learners' diaries.

Discourse analyses of cross-cultural communication have also used a predominantly hermeneutic approach and include book-length accounts by Agar (1994) and Scollon and Scollon (1995), the collection of articles in Bremer, et al. (1996), as well as several articles reviewed below. Also within this tradition are book-length ethnographies of bilingual communities such as Goldstein's (1997) study of Portuguese migrant workers in a Canadian factory, Losey's (1997) study of Mexican American students in a California community college, and Zentella's (1997) study of the Puerto Rican community of New York's Spanish Harlem. If hermeneutics is art, then we must also include here among the scholarly studies the astute, biting, and often painfully funny representations of multicultural life on "The New World Border" in the performance art of Guillermo Gómez-Peña (1993; 1996).

Conversation analysts trained in ethnomethodology have been perhaps the most skeptical of the role of quantification in understanding talk-in-interaction because of the ethnomethodological axiom that particular instances of talk-ininteraction must be understood from the point of view of the participants in the interaction. Schegloff (1993), for instance, reflects on the use of one numerical measure, the ratio (so many tokens of a certain type spread over a certain field of measurement, say, tokens of laughter per minute), in the analysis of talk-ininteraction:

Quantitative analysis requires an analytically defensible notion of the denominator. I will call it "environments of possible occurrence," or, more explicitly, "environments of possible relevant occurrence."...Second, quantitative analysis requires an analytically defensible notion of the numerator, the set of types of occurrences whose presence should count as events and...whose non-occurrence should count as absences. That requires...an understanding of what sorts of occurrences or practices are alternatives to one another for the participants. Third, quantitative analysis requires an analytically defensible notion of the domain or universe being characterized. Here I refer...to...relevant organizational domains of activity for the participants in interaction (1993:103).

As it appears from this quotation, an ethnomethodologist's notion of "context" involves understanding how participants in a particular interaction negotiate or achieve a common context-what has been called intersubjectivity (Rommetveit 1985; 1987). When adopted by a second language acquisition researcher, this approach typically results in an in-depth analysis of a single conversation. 
Although the distinction between quantitative and interpretive approaches that I have sketched is one maintained by a majority of researchers, a minority has combined both quantitative and qualitative approaches in the same study. Some studies of conversational phenomena, for instance, begin with a frequency count of the phenomenon in question and then go on to a qualitative analysis of particular instances of talk. This is the approach taken by Berry (1994), Gardner (1998), and Young and Halleck (1998).

\section{INTERLANGUAGE VARIATION}

SLA variationists have used quantitative, correlational analyses to express the relationship between variable linguistic forms in interlanguage and co-occurring elements of social and linguistic context. For some years now it has been known that the apparently random and even obstinate behavior of bilinguals in sometimes using one form and sometimes another is in fact systematically related to the contexts in which the forms are uttered. Nonetheless, some years ago, a rather unproductive debate was joined between proponents of Universal Grammar in SLA and variationists as to whether such relationships are of any theoretical interest (Ellis 1990, Gregg 1990, Tarone 1990). Gregg maintained that then-current notions of linguistic competence did not admit the possibility of variation, which is a feature of performance; and since performance is outside the domain of the linguistic theory that interested Gregg, ergo variation is of no theoretical interest. In responding to Gregg, Ellis maintained that variation is in fact part of the linguistic competence of L2 learners, while Tarone suggested that the competence/ performance distinction is unnecessary. The debate was unproductive because neither side was able to bring data to bear on the issue. Eckman (1994), in an illuminating and balanced commentary on the debate, concluded that neither side presented compelling arguments in its favor: "Proponents of the competence model...cannot in principle demonstrate that no important insights would be forthcoming by including data from variation. On the other hand, proponents of the variationist model have not as yet presented the kind of data that would be most convincing for their position. The question is an empirical one, and its resolution must await the presentation of such data" (1994:14).

Since Eckman's remarks, a number of empirical studies of interlanguage variation have been published that have provided some support for the position that systematic variation in an individual bilingual's interlanguage is essential to the development of interlanguage. These discoveries parallel the discovery in studies of diachronic linguistics that historical change in language would not be possible were it not for the existence of patterned synchronic variation (Weinreich, Labov and Herzog 1968). Young (1996) found evidence, in the acquisition of the English definite article by Czechs and Slovaks, that learners' acquisition of 'the' initially results in random patterns of free variation which in later development resolve themselves into systematic patterns-an important developmental mechanism predicted by Ellis $(1985 ; 1989)$. Particular influences of social context on development were found in two other studies: Bayley (1996), in a study of final 
'-t/d' deletion in the speech of Chinese-English bilinguals resident in California, found that speakers whose social network consisted predominantly of other Chinese delete final ' $-\mathrm{t} / \mathrm{d}$ ' more often than speakers who report a mixed Chinese and American social network. Regan (1996) measured the rate of ' $n e$ ' deletion in the French negator ' $n e$... pas' of Irish university students acquiring French as a foreign language before and after their year abroad in France. She found that, irrespective of their overall proficiency in French, students' rate of 'ne' deletion increased dramatically after their year in France.

The most interesting of these studies of intra-individual variation and its role in interlanguage development is Liu's (1991) dissertation study of a Chinese child acquiring English as his second language in Australia, summarized in Tarone and Liu (1995). Tarone and Liu show that certain kinds of interaction that the child engages in encourage faster and more complete development of features of his interlanguage than other kinds of interaction. A similar finding is reported by Shea (1994), who compares interactions between Japanese students studying at an American university and four different interlocutors. Shea reports that the Japanese students appear more proficient in English in conversations where they have equal access to the floor and take perspectives that are congruent with those taken by their interlocutor. Shea explains the differential fluency of the Japanese bilinguals with different interlocutors by reference to the Vygotskyan notion of scaffolding (Cazden 1988) and Rogoff's (1990) theory of guided participation. As Shea remarks, "The collaborative activity in which the teacher (or more experienced peer) sustains the learner's activity within the 'zone of proximal development' (Griffin and Cole 1984, Vygotsky 1978) is the critical means of cognitive growth" (1994:378).

In contrast to the interactive perspective on interlanguage production provided by Tarone, Liu, and Shea, a more monologic perspective is provided by Douglas and Selinker's discourse domain theory (Douglas and Selinker 1985; $1992 ; 1993 ; 1994 a ; 1994 b$, Selinker and Douglas 1985; 1989). A discourse domain is defined by Whyte (1995:158) as a topic area in which the speaker has both extensive knowledge and current kowledge, and in which the speaker is emotionally invested. The prediction of discourse domain theory is that, when speaking on discourse domain topics, bilinguals will produce second-language talk that is more complex, more independent, and more coherent than when they speak on general topics. Although several researchers (Mora 1995, Zuengler 1989, Zuengler and Bent 1991) have framed their studies to take discourse domains into account, in the only published test of discourse domain theory, Whyte (1995) finds only partial support for the theory. The reason for the only partial support may be that discourse domain theory does not take the essential role of the speaker's interlocutor into account. According to He and Young (1998), Jacoby and Ochs (1995), and McNamara (1997a), bilinguals' performance in spoken interaction is mediated-or co-constructed-by their interlocutors, an interactional dimension that discourse domain theory fails to take into account. 


\section{CROSS-CULTURAL COMMUNICATION}

In the past five years, several book-length studies and anthologies have been published that adopt a discourse approach to cross-cultural communication, the most notable of which are Agar (1994), Bremer, et al. (1996), and Scollon and Scollon (1995). Although studies of cross-cultural communication have been an important focus of second language acquisition research almost since its inception, as Firth and Wagner (1997) comment, the great majority of studies have been of learners in a formal school setting, and, in many cases, the focus of research has been on the bilingual individual's perceived linguistic deficiencies and communicative problems. The traditional practice of referring to one participant in an interaction as "native" and the other as "non-native" has been symptomatic of the way in which a bilingual's linguistic performance is viewed as problematic and less acceptable than the native interlocutor (cf. Paikeday 1985). In recent years, however, there has been greater emphasis on cross-cultural communication as an accomplishment of both parties in a conversation and on a bi-directional interpretation of communication difficulties that takes both interlocutors' perspectives into account (Singh, Lele and Martohardjono 1988). The studies reviewed here all view cross-cultural communication as a mutual accomplishment and many focus on communication in a non-instructional setting.

Problems in the cross-cultural communication of referential meaning have been the focus of studies on the negotiation of meaning (see recent reviews by Braidi 1995 and Pica 1994) and, until recently, research in communication strategies also focused primarily on the communication of referential meaning. More recently, however, a number of studies of communication strategies have examined the use of strategies to attain pragmatic or relational goals (Kasper 1997, Rampton 1997, Wagner and Firth 1997, Williams, Inscoe and Tasker 1997). In keeping with this approach, many of the studies reviewed here focus not on the communication of referential meaning but on interpersonal dynamics, the presentation of self, the multiple functions of a situated utterance, and the ways in which intersubjectivity is jointly constructed through interaction.

As mentioned above, the dominant research methodology in the analysis of cross-cultural communication has been hermeneutic and qualitative. A small number of studies, however, have used more traditional social science methods such as questionnaires. Ebsworth and Ebsworth (1997), for instance, used a questionnaire to compare responses to five critical situations by Island Puerto Ricans and Continental Americans from the New York area (a complaint from a customer, divulging personal information to a stranger, insults to a person's mother, the experience of gender bias, and how to handle obligations to friends). Hinkel (1994) and van Betteraij and Kellerman (1996) also used questionnaires to compare and contrast which topics of informal conversation are preferred by different cultural groups. 
The qualitative studies have generally shown that the communication of referential information in cross-cultural communication is not as problematic as might be believed. Cameron and Williams (1997) analyze professional medical encounters between a Thai nurse-trainee and two patients and between the nurse and her supervisor. Although breakdowns in referential communication are apparent in the interactions, Cameron and Williams emphasize how they are successfully resolved. Cameron and Williams conclude that miscommunications are overcome because of 1) ordinary inferential responses of the hearer, which are predictable by relevance theory (Sperber and Wilson 1995), 2) the nurse's use of communication strategies, and 3) the nurse's own emerging professional competence, which not only influences the negotiation of meaning but also guides the interaction toward her goals as a medical professional. Gallego (1997) also examines communication difficulties between a bilingual professional and her monolingual clients. He analyzes professional office-hour interactions between international teaching assistants and students in the economics department of an American university. Gallego finds that misunderstandings arise both because of linguistic difficulties of ITAs as well as because of difficulties with the disciplinespecific topic of the office hour. Language-related problems are rare, however, and they are quickly repaired. (In 10.5 hours of videotaped interaction, Gallego finds only 12 instances.) Misunderstandings caused by the content of the TA's explanations are much more frequent and require much longer sequences of talk to repair. Gallego concludes with a practical suggestion for the selection of international TAs: “The question to ask about an NNSTA with a minimum level of language proficiency...is not how good are his/her language skills, but what are his/her presentation (i.e., teaching) skills like?" (1997:191).

The success of the communication reported in these two studies may be attributed in part to the bilinguals' expertise in their professional areas. A contrasting study by Liberman (1995) provides a fascinating insight into the difficulties of a bilingual student studying in a second language with monolingual teachers. Liberman reports conversations he had in Tibetan with Tibetan monks while studying Buddhist philosophy in a traditional monastic university in South India. As a novice, he had difficulty understanding some of the technical concepts in the field and he reports that his own participation included a lot of "gratuitous concurrence, that is, facile agreement with utterances that are not comprehended" (1995:121). Liberman's experience contrasts with that of the Thai nurse in Cameron and Williams's (1997) study because, while the nurse used her subjectspecific expertise to overcome communication difficulties, Liberman found that he used his interactional expertise to conceal his lack of understanding of the subject matter and he concludes, "Local interactional concerns and obligations can and usually do overshadow the semantic issues" (1995:139).

Cross-cultural miscommunication may have negative social consequences for the bilingual participant, particularly in gate-keeping encounters where a native speaker controls the non-native speaker's access to some desired outcome. A gatekeeping encounter that has been extensively studied of late is the language 
proficiency interview (LPI) in which a native-speaking interviewer assesses a bilingual candidate's ability to speak a second language (Young and He 1998). Kim and Suh (1998) analyze LPIs involving American learners of Korean; Ross (1998) studies LPIs involving Japanese learners of English; and Young and Halleck (1998) compare Japanese and Mexican learners in English LPIs. A common finding of these researchers is that bilinguals transfer conversational styles from their L1 into the L2. Some features of the transferred L1 conversational style are judged negatively by the interviewer-who is a native speaker of the L2-resulting in low assessments of the candidate's L2 proficiency. For instance, Japanese interviewees often respond minimally to questions posed by the interviewer whereas Mexicans tend to respond at greater length; other things being equal, this outcome results in a lower assessment of the English proficiency of the Japanese interviewee. In contrast, Americans speaking Korean sometimes fail to acknowledge the interviewer's higher status and provide more information than is required, a style that results in a low assessment of their proficiency in Korean.

In the context of widespread racial and economic discrimination, crosscultural miscommunication can have serious and damaging social consequences. The increasing hostility between individuals, as each side's negative judgement of the other's communicative style confirms and reinforces their initial prejudices, was described by Bateson (1972) as "complementary schismogenesis." An excellent analysis of just such encounters between Korean shopkeepers and African-Americans customers in South Central Los Angeles is provided by Bailey (1997). Several researchers, however, have criticized explanations of crosscultural miscommunication that rely solely on the different preferred cultural values and conversational styles prevalent in the two cultures. The critics point out that, in modern societies, individuals' identities are complex and fluid (Sarangi 1994), ideologies about a particular group may influence individuals to be tolerant or intolerant of communication difficulties (Meeuwis 1994), and there is a great deal of diversity and conflict within any one culture (Shea 1994).

\section{CONVERSATIONAL PHENOMENA}

The study of conversation is important for sociolinguists because, as Schegloff (1987) and other conversation analysts have stressed, conversation "operates in, and partly organizes...the primordial site of sociality: direct interaction between persons" (p. 208). Micro-level conversational features such as overlap, back channeling, pausing, and topic choice are examined in the following studies. In most of the SLA research under this heading, features of conversations involving monolingual English participants are compared with conversations involving either learners of English or else speakers of other languages. The comparisons and contrasts are made with a view to identifying possible sources of transfer from $\mathrm{L} 1$ into $\mathrm{L} 2$ and to understanding miscommunication in cross-cultural encounters. 
Both Gardner (1998) and White (1997) report on back channeling (also known as receipt tokens). Gardner describes the functional distinctions in English among 'yeah/yes,' 'oh,' 'mm hm/uh huh,' 'mm,' 'right,' and 'okay' and compares the use of these forms by monolinguals and bilinguals. He reports that, overall, non-native speakers of English use fewer receipt tokens in English than native speakers with the exception of 'yeah,' a finding that is confirmed by White's (1997) study of business negotiations between Japanese and North Americans.

An explicit comparison of conversational features in two languages is provided in Berry's (1994) study of Spanish and American turn-taking styles. Berry analyzed two separate dinner party conversations, one involving four American women speaking in English and another involving four Spanish women conversing in Spanish. Berry found that about half of the utterances in both Spanish and English conversations began with overlaps, but there was a big difference in the length of the overlap: The average overlap in English had a length of 2.88 syllables, while the average overlap in Spanish lasted 4.56 syllables. The different turn-taking styles in the two languages may lead to misunderstandings as Berry found when she asked for each group's opinion of the other group after presenting the other dinner conversation to them. Participants very often came to wrong conclusions concerning the personalities of the women in the other group. Long overlaps were considered as impertinent by the American women, whereas the Spanish women inferred from the American women's short overlaps that they were not enjoying themselves.

One other area of comparative research into conversational phenomena is discourse socialization, that is, how children in different communities learn ways of speaking that are situationally appropriate in the community and internalize the social values that community members manifest through talk. Much of the early work in this field was carried out by linguistic anthropologists who examined in detail the child-rearing practices of a particular community and how these practices influenced children's ways of speaking (Clancy 1986, Ochs and Schieffelin 1979, Schieffelin and Ochs 1986). More relevant to SLA, because of the implications for transfer, are explicit comparisons of discourse socialization practices in different communities such as described in Aukrust and Snow (1998). Aukrust and Snow analyze the explanations and narratives co-constructed by parents and three-yearold children during mealtime conversations in middle-class Norwegian and U.S. families. Their findings included the following: 1) Norwegian conversations contain more narratives than conversations in the U.S., while American conversations contain more explanations; 2) Norwegian families' explanations focus on social practices, while families in the U.S. focus on reasons for behavior (including internal mental states); and 3) Norwegian narratives focus more on local events, while American narratives incorporate events in more distant contexts. Aukrust and Snow conclude that the habitus (shared dispositions, understandings, routines, and practices-Bourdieu 1991) of Norwegians involves homogenization, equality, and belongingness to the local community-and is implicit, while that of 
families in the U.S. explicitly foregrounds civic values such as democracy, freedom of choice, equal opportunities, individualism, and distrust of the state.

\section{$\underline{\text { SOCIAL IDENTITY }}$}

The concept of an individual's social identity has been invoked by several researchers as a way of viewing and explaining the patterns of language use and the language attitudes of bilinguals. (See McGroarty 1998 for a review.) Unfortunately, however, most SLA researchers appear to use social identity in a pre-theoretical way in their reports and have not given a clear definition of exactly what social identity is or how it arises and changes. A notable exception is McNamara (1997b), who proposes a dynamic view of social identity in the context of intergroup relations as arising from four main processes. Basing his theory on Tajfel (1981), McNamara identifies the four processes as "(a) social categorization, (b) the formation of an awareness of social identity, (c) social comparison, and (d) a search for psychological distinctiveness" (1997b:562). Other researchers, rather than saying what social identity is, have emphasized that bilinguals participate in multiple and shifting identities:

Everywhere, cultural identities are emerging which are not fixed, but poised, in transition between different positions; which draw on different cultural traditions at the same time; and which are the product of those complicated cross-overs and cultural mixes which are increasingly common in a globalized world (S. Hall 1992:310).

This is a situation imagined by Gómez-Peña (1996) in his poem, Freefalling toward a borderless future:

I see a whole generation

Freefalling toward a borderless future

Incredible mixtures beyond science fiction:

Cholo-punks, pachuco krishnas,

Irish concheros, butoh rappers, cyber-Aztecs,

Gringofarians, Hopi rockers, y demás ...

The ways that bilinguals use and choose language in linguistically diverse societies contribute to the process of social identity formation such that, for a bilingual, each act of speaking or silence becomes an "act of identity" (Le Page and Tabouret-Keller 1985). Two book-length ethnographies of bilingual communities, by Zentella (1997) and by Losey (1997), stress the complex ways in which social identities are constructed in multilingual settings. Zentella (1997) describes the patterns of English and Spanish use and code-switching in a Puerto Rican community in New York's Spanish Harlem. She reports conflicting views within the community of the role of Spanish language use in the formation of a Puerto Rican identity. In contrast, Schechter and Bayley (1997), in interviews with four Mexican American families, found that all individuals accorded Spanish an 
important role in the formation of cultural identity. Losey (1997) focuses on interactions in a community college classroom in a small agricultural community in California between Mexican American students and their Anglo American teacher and other Anglos in the community. What she notices is not language use but the silence of the students, a silence that is actively co-constructed by the Anglo community-not a silence, but a silencing. She relates the lack of classroom contributions of the bilingual students to Mexican-Americans' lack of political power in the community. Other commentators have described similar marginalization of bilingual individuals in terms such as "othering" or "outing" (Leung, Harris and Rampton 1995) and the interactional consequences of this have been skillfully described by Tai (1996).

Peirce (1995) also criticizes conceptions of static social identity and fixed group differences in her study of female immigrants to Canada. Peirce describes an individual's social identity as a site for struggle that results in changes in identity. She gives the example of a Czech woman, Martina, who came to Canada for a better life for her children. Although, in many interactions with Canadians, Martina felt uncomfortable speaking English, on one occasion when she perceived a threat to her home, she spoke with her landlord less tentatively: "on the phone over one hour and I didn't think about the tense rules. My children were very surprised when they hear me" (p. 22). Another example Peirce gives is of Eva, a Polish woman who immigrated to Canada for economic advantage: "Over time... Eva's conception of herself as an immigrant-an 'illegitimate' speaker of English-changed to a conception of herself as a multicultural citizen with the power to impose reception" (1995:23-24).

Gender can be one of the most powerful components of an individual's social identity, and the way that participants in cross-cultural communication orient to female gender has been investigated in a number of articles. Early studies of language and gender associated certain linguistic patterns with men's speech and women's speech (cf. also the recent study by Losey 1995), but most recent research rejects such a clear-cut and static distinction. In a review of gendered speaking practices across different communities, Günthner (1996) finds that "the relationship between linguistic features or communicative styles and gender is not as unilinear as formerly assumed" (p. 447). Participants to an interaction are thus not relevantly male or female, but they may "do gender" through the interaction, and different social events may foreground different aspects of social identity such as ethnicity or status as well as gender. Günthner concludes that "in most communities gender is not marked directly, but gender indexing is indirect, i.e., by means of other connections between gender and habitual speaking practices, [and] simple correlations between linguistic features and social structures are bound to fail" (1996:466). In some cases reported in the recent literature, doing female gender in a second language is also a site for struggle, "a struggle which takes place in the consciousness of the individual" (Weedon 1997). Siegal (1996) shows how a female bilingual can resist the typical female interactional roles expected in a different culture and community. Ehrlich (1997) agrees, saying that gender (and 
other social categories that are applied to social actors) is not a given but is constructed by individual actors in specific social situations: "Individuals construct themselves as 'gendered' by habitually engaging in the social practices of a speech community that are symbolically and practically associated with masculinity and femininity or some mixture thereof" (1997:440). In a similar argument, with a more nuanced analysis of gender and its interactions with other linguistic and social phenomena, Freed (Freed 1996, Freed and Greenwood 1996) suggests that language and gender studies conducted in natural settings may often find differences between women's and men's speech simply because women and men are frequently engaged in different activities and not because of any differences in women and men themselves.

\section{SOCIOLINGUISTIC THEORIES OF SLA}

Sociolinguistics is perhaps the branch of linguistics least concerned with theory construction. Charles Ferguson (1997), one of the founders of the field, reflects that from its earliest days, sociolinguistics was problem driven rather than theory driven. Emanuel Schegloff (1987), too, rejects unitarian theories in the social sciences until “some 'depth' is achieved by determining how some described phenomenon differs in different social classes and cultural settings, or under different work conditions" (p. 228). Similarly, sociolinguistic approaches to SLA have also been lacking in the kinds of overarching theories beloved of syntacticians and cognitive psychologists. It is perhaps appropriate, then, that this review concludes rather than commences with a survey of sociolinguistic theories of SLA.

It is certainly true that no coherent or explicit theory of the sociolinguistics of second language acquisition has been advanced so far, and given the immense complexity of the phenomena of interlanguage variation, cross-cultural communication, conversational phenomena, and social identity, this is perhaps not surprising. Nonetheless, several scholars have sketched proposals for what theories of part of the field might look like. I will review below three theories that have received attention in the past five years: discourse domains, co-construction, and interactional competence.

The theory that makes the most specific predictions about bilingual performance is that of discourse domains (Douglas and Selinker 1985; 1994a, Mora 1995, Whyte 1994a; 1994b; 1995, Zuengler 1989). This theory predicts an association between accuracy of production in a second language and discourse topic, and it has been discussed above under the heading of interlanguage variation. As we have seen, the weakness of discourse domain theory lies in its focus on an individual participant in an interaction and that individual's psychological reactions to certain topics and themes.

Two other theories have taken a broader view, seeing social and sociolinguistic phenomena as co-constructed by all participants to an interaction. Co-construction is a term introduced by Jacoby and Ochs (1995), who define it as 
"the joint creation of a form, interpretation, stance, action, activity, identity, institution, skill, ideology, emotion, or other culturally meaningful reality" (1995:171). Although the term co-construction may suggest that joint creations are made by means of cooperative or supportive interaction, Jacoby and Ochs make clear that co-construction is not necessarily affiliative or supportive interaction: An argument, for example, is just as much co-constructed as a conversation. Tarone (in press) adopts a similar view in explicitly rejecting the traditional focus of SLA studies on an individual learner, and she illustrates co-construction with an appealing metaphor. She contrasts two images: the learner as an isolated solver of jigsaw puzzles (a view she attributes to theorists who see SLA as a purely cognitive enterprise) and the learner as a dancer, learning to dance by means of dancing and attending differently to different partners who, in their turn, are differently sensitive to the movements of the learner. She draws evidence in support of her view from Tarone and Liu (1995) and from Tarone and Swain (1995), who argue that different-age children in immersion programs pay different attention to input from their teachers and from their peers: Pre-adolescents attend more to the vernacular L1 of their peers, while younger children attend more to the academic L2 register of their teachers. Tarone also sees support for her position in recent work in neuropsychology, such as that reviewed in Schumann (1997), which claims that all attention, cognition, and long-term memory is mediated by the affective appraisal of stimuli. Since different social situations give rise to different affective responses, the input a learner receives is differently attended to and differently processed. In stimulus appraisal, Tarone has identified a possible mechanism underlying variation in the rate and route of second language acquisition by different learners in different social contexts. The problem with such a theory is that, although it is possible to see in retrospect the effects of an individual's history of stimulus appraisal in learner biographies, the theory has, for now, little predictive power because the effects of individual instances of stimulus appraisal and affective encoding are as yet little understood.

Co-construction is also one of the foundations of interactional competence, a theory developed in slightly different versions by J. K. Hall (1993), He and Young (1998), Kramsch (1986), and Psathas (1989). Interactional competence is a theory of the knowledge that participants bring to and realize in interaction and includes an account of how such knowledge is acquired. In this theory, secondlanguage knowledge is considered to exist not within the mind-brain of a single participant; rather, it is considered to be jointly constructed in interaction. In this respect, interactional competence differs fundamentally from communicative competence as elaborated by Bachman (1990) and Canale and Swain (1980), with its traditional view of second-language competence as a trait that is predicated of a single individual. A second assumption of the theory is that interactional competence is located in specific instances of interaction-what J. K. Hall (1995) has called "interactive practices." Interactive practices are recurring episodes of talk that share a particular structure and are of sociocultural significance to a community of speakers. Interactive practices are closely related to Hymes's (1974:12-16) notion of "communicative events" and can include, for example, a 
job interview, a radio broadcast of a baseball game, a university office hour, and a language proficiency interview. Each instance of an interactive practice is coconstructed by participants who draw on interactional resources to accomplish the practice. Several kinds of interactional resources have been specified and include participants' knowledge of rhetorical scripts (Ranney 1992), participation frameworks (Goffman 1981), practice-specific lexis and syntactic structures, participants' strategies for managing turns and topics, and participants' knowledge of ways of signaling the boundaries of a practice, including the opening, closing, and practice-internal transitions. The structure-architecture really-of a given interactive practice consists of the ways in which these resources are exploited and combined by participants.

How is interactional competence acquired? Individuals become participants by watching and participating in specific instances of a given practice. As J. K. Hall (1995) puts it, "Our becoming participants involves three processes: the discovery (other- and self-guided) of interactive patterns in the practices in which we engage with others; observation and reflection on others' participatory moves and the responses to these moves; and our own active constructions of responses to these patterns" (1995:218). Because knowledge and interactional skills are local and practice-specific, the joint construction of an interactive practice involves participants making use of the resources they have acquired in previous instances of the same practice. An important corollary of this is that individuals do not acquire a general, practice-independent communicative competence; rather they acquire a practice-specific interactional competence by participating with more experienced others in specific interactive practices.

Interactional competence is thus a theory that specifies in some detail what learners need to know in order to participate with others in the interactive practices that constitute life in the social world. As such, it is a theory of second-language knowledge. Interactional competence also explains the processes by which learners become participants in the social world, and, as such, it is a theory of acquisition. The domain of the theory is face-to-face interaction, and, of the four areas of sociolinguistic research into SLA reviewed in this article, interactional competence is clearly most applicable to explaining cross-cultural communication. It also provides a convenient framework for integrating studies of conversational phenomena within a broader context of interaction. Social identity, insofar as it is co-constructed through interaction, also falls within the domain of theory. The theory is apparently not-or not yet-helpful in understanding interlanguage variation. At this point, however, no empirical studies have been carried out to test the claims of the theory. We have, as yet, very few detailed descriptions of the configuration of interactional resources that constitute the interactional architecture of a given practice. The co-constructed nature of interactional knowledge poses a serious dilemma for language testing, which is built on the basis of knowledge as an individual trait (McNamara 1997a). And we await descriptive and pedagogical studies of how novices become expert participants and the degree 
to which interactional competence in a given practice can be generalized to other practices. There is, thank goodness, much work still to be done.

\section{NOTES}

1. Throughout this article I use the term "bilingual" to refer to someone who knows a second language to at least a minimal degree. By using this term, I wish to avoid the connotations of deficit that attach to the more common term, "nonnative speaker."

\section{ANNOTATED BIBLIOGRAPHY}

Bailey, B. 1997. Communication of respect in interethnic service encounters. Language in Society. 26.327-356.

Bailey describes face-to-face service encounters between Korean (K) shopkeepers and Afro-American (A-A) customers in Los Angeles. He contrasts the negative politeness ("restraint") of $\mathrm{K}$ retailers with the positive politeness ("involvement") of A-A customers. In the socially and racially charged atmosphere of LA, this interaction can affect relations between groups. The service encounters between $\mathrm{K}$ shopkeepers and $\mathrm{K}$ customers are short and to the point; neither side engages personally with the other. In contrast, encounters with A-A customers are longer and involve the $\mathrm{K}$ shopkeepers reacting (not pro-acting) to co-construct the conversation. $\mathrm{K}$ retailers do not align themselves with A-A customers' emotional stances in interaction, and this reflects the Ks' limited English proficiency as well as the $\mathrm{K}$ restraint politeness system. In contrast, A-A "involvement politeness requires more complex verbal activities-e.g., using in-group identity markers, showing interest in the other's interests, and joking" (pp. 338-339). A particular conversational feature in which the two politeness systems contrast is back channeling: In comparison with animated A-A back channels, $\mathrm{K}$ retailers display little response to A-A customers' assessments. Bailey concludes, "Mismatch in politeness orientations can have a self-reinforcing, spiraling effect that exaggerates differences in politeness style as interaction continues; this can exacerbate misunderstandings and mutual negative evaluations" (p. 352). 
McNamara, T. F. 1997a. 'Interaction' in second language performance assessment: Whose performance? Applied Linguistics. 18.446-466.

In an interesting discussion, McNamara outlines the implications of recent applied linguistic theories of interaction for language testing. He rejects the static way that social interaction has been incorporated into tests in rating scales, representing dimensions of an individual's cognition and ability. With Halliday (1978), McNamara rejects the way that the social is transformed into an aspect of the cognitive organization of the individual in Hymes's (1972) conceptualization of "communicative competence" as the knowledge of an individual speaker-hearer. Instead, he proposes that the dynamic and co-constructed nature of interactions should be considered in language assessment. This clearly poses great problems for assessors who wish to generalize from an instance of an interaction to an individual's ability because, if communicative events are co-constructed, how are we to generalize from these actual instances given the effect of the other parties in the interaction? McNamara makes four recommendations for assessment based on a co-constructed view of interaction: 1) apply the standards of real interaction rather than those of language testers, 2) dispense with simulated interaction because it may in fact distort crucial aspects of the real life performance it is supposed to mimic, 3) recognize that judgments are framed and idealized by raters-that is, raters have a point of view, and 4) recognize that, if communication is a joint responsibility, then when communication goes awry, part of the blame must be assigned to all participants.

Shea, D. P. 1994. Perspective and production: Structuring conversational participation across cultural borders. Pragmatics. 4.357-389.

In this clear and well written article, Shea argues persuasively against Gumperz's theory of cross-cultural communication (Gumperz 1990; 1992, Gumperz and Roberts 1991). According to Shea, Gumperzian analysis of intercultural interaction has two primary features: contextualization cues and speakers' inferences from those cues. Contextualization cues are metalinguistic signals that indicate the frame within which talk-ininteraction is interpreted and include paralinguistic signals of intonation, stress, and rhythm, as well as choice of code and register. The inferences that speakers draw from these cues are, according to Gumperz, determined by their conventional meaning within a particular speech community. The same cue can have different meanings to different cultural groups and this is the basis for miscommunication, a miscommunication which may lead to negative feelings about the speaker since speakers are rarely consciously aware of the relationship between cues and their culture-specific inferences. Shea makes two criticisms of Gumperz. First, as Meeuwis (1994) has argued, participants bring to interaction pre-existing ideologies and prejudices. Their interpretation of contextualization cues may be 
biased by their ideological view of the group to which they perceive their conversational partner to belong. This leads to greater tolerance (leniency) of miscommunication in interactions with prestige groups but less tolerance (testiness) in interactions with members of a socially marginalized group. Second, in talking of culturally-specific interpretations of contextualization cues, Gumperz fails to recognize the heteroglossic nature of modern societies, in which there is no unified native-speaking speech community. Shea advocates a more dynamic theory than Gumperz in which a speaker's positioning rather than a speaker's position is analyzed. Adopting Rommetveit's $(1985 ; 1987)$ notion of intersubjectivity, Shea describes two dimensions of interaction by which participants in dyadic conversations create intersubjectivity: equal/unequal access to the conversational floor and congruent/ noncongruent perspectives. Shea illustrates these four kinds of interactions by analyzing conversations in English involving Japanese students in an American university setting. Shea's analysis echoes Tarone and Liu (1995) in remarking that non-native speakers appear more proficient in English in conversations where they have equal access to the floor and take perspectives that are congruent with those taken by their interlocutor.

Siegal, M. 1996. The role of learner subjectivity in second language sociolinguistic competency: Western women learning Japanese. Applied Linguistics. $17.356-382$.

Adopting Goffman's (1956) theory of presentation of self through face, deference, and demeanor, Siegal describes an interaction in Japanese between a professional New Zealand woman learning Japanese in Japan, and her male Japanese professor. According to Siegal, the presentation of self in an L2 is difficult because a bilingual individual may not know the L2 pragmatic rules and/or they may reject certain L2 norms of behavior. This situation may lead the individual to create a face that they do not intend or to create a face that is outside the guidelines of appropriate behavior in the L2 community. Siegal's subject, Mary, is ambivalent about the traditional gender role assigned to women in Japanese society, which she calls "too humble...too silly," and she resists the hesitancy expected of a polite Japanese female, referring to it as a "shuffle." Mary presents herself as a professional while speaking with her professor by guiding the range of topics that are covered in the conversation. At the same time, she uses polite language and demeanor but sometimes inappropriately; for example, she uses sing-song cheerfulness at the end of the encounter, which is more appropriate for service personnel. Her professor does not seem to be dismayed by her pragmatic inappropriateness and co-constructs a successful encounter. Siegal concludes, "Language learners manipulate conversations to create face, their image within a particular conversational interaction. This manipulation occurs using an imperfect interlanguage and involves modality, honorific 
language, and topic control. A learner's 'pragmatic incorrectness' might be attributed to a desire to buck societal conventions" (p. 374).

Tai, E. 1996. Passing as a native in social interaction: Taiwanese in a changing Japanese society. Research on Language and Social Interaction. 29.97-123.

Working within Goffman's (1963) framework of stigma, Tai analyzes a conversation in Japanese between an oldcomer Taiwanese immigrant to Japan and a Japanese taxi driver. Taiwanese immigrants often occupy low socioeconomic positions in Japan and prejudice against them by Japanese is prevalent. These stigmatic conditions exist in advance of interaction, and in Goffman's framework, people with stigmatic attributes manage to conceal or reduce their differentness in social interaction by using techniques of information control and the strategies of passing and covering. Tai shows how this is done by her Taiwanese subject, Kasai, whom she observes on his way to the airport to catch a plane to Taiwan. When asked by the taxi driver if he is Taiwanese, Kasai claims that he is Japanese. However, Kasai cannot pass linguistically as a Japanese because his speech differs phonologically, syntactically, and in conversational features from Japanese. Kasai also claims high status by telling the taxi driver that he is a doctor and that his son is studying at medical school in America. According to Goffman, this is the most effective kind of covering (the adaptive technique of reducing tension associated with a stigma), displaying status symbols that would compensate for the stigma and thereby soften its effect. Tai sums up the interaction as follows: "Kasai constructed an interactional context as a site of negotiation for ethnic identity. He made a claim to Japanese identity; he shifted conversational topics to his advantage while keeping the natural flow of the conversation. However, he had difficulty achieving his goal because of language problems" (p. 118). Tai concludes that by accepting stigma, Kasai may have intensified it: "He might have inadvertently reinforced the myth of the superiority of the Japanese people, precisely because he attempted to pass as Japanese" (p. 120).

Tarone, E. and G.-q. Liu. 1995. Situational context, variation, and second language acquisition theory. In G. Cook and B. Seidlhofer (eds.) Principle and practice in applied linguistics: Studies in honour of $H$. G. Widdowson. Oxford: Oxford University Press. 107-124.

Tarone and Liu report on Liu's (1991) study of "Bob"-a young Chinese boy acquiring ESL in Australia. The linguistic form analyzed is question formation within Pienemann and Johnston's (1987) six-stage theory of the acquisition of English interrogatives. A longitudinal study of Bob's questions to different interlocutors shows that both the rate and the route of the learner's acquisition of English question formation depends on the 
social role that the learner plays with different interlocutors. In particular, almost every new stage of question formation appears in one particular interactional context: in conversations between the child and the researcher. Tarone and Liu interpret Bob's interlanguage development by appealing to Swain's (1985) output hypothesis, noting that the communicative demands of certain interactional contexts force interlanguage to develop in order to meet those demands. Without such demands the learner's interlanguage may fail to develop.

White, R. 1997. Back channelling, repair, pausing, and private speech. Applied Linguistics. 18.314-344.

White analyzes back channeling, repair, pausing, and private speech in business negotiations between Japanese bilinguals and English-speaking North Americans. Ten nationally mixed role-play dyads were set up with most of the North American participants in the buyer role and the Japanese in the seller role. Results showed that back channel cues (BC) most often occurred at the end of an utterance. Japanese participants produced more BCs than the North Americans, while the North Americans used a wider variety of $\mathrm{BC}$ tokens. White also analyzes pauses and found a lot of pausing in the negotiations because business negotiations are cognitively complex tasks. As both Japanese and North American participants required time for their tactical plans, pauses of up to 30 seconds were found, much longer than the normal three-second pauses found in informal conversation. The long tactical pauses, White claims, are a means of expressing power over the other party and are very often used by the Japanese negotiators. Another aspect White analyzed was private speech (PS). This feature was common in the speech of the North Americans but only rarely used by the Japanese. The North American participants sometimes used PS as a negotiating tactic, with which the Japanese were apparently unfamiliar. White concludes by comparing Japanese and North American participants' use of these conversational features and believes that "norm differences can...result in a fundamental mismatch of objectives and process" and "the hidden effects of conversational form can affect participants' attitudes and negotiating outcomes" (p. 338).

Whyte, S. 1995. Specialist knowledge and interlanguage development: A discourse domain approach to text construction. Studies in Second Language Acquisition. 17.153-183.

Whyte operationalizes and tests Selinker and Douglas's discourse domain (DD) hypothesis (Douglas and Selinker 1994b, Selinker and Douglas 1985). A DD is defined as "a topic area that is characterized by extensive knowledge..., by important knowledge..., and by current knowledge" (p. 158). It is thus a psychologically defined construct related to expertise, investment, and currency of a topic for an individual. Whyte improves on 
Selinker and Douglas's original formulation by recognizing the circularity inherent in their DD hypothesis: "Learners are observed to perform differently in domain talk because they are talking on domain topics, and topics are identified as discourse domains because of this differential performance." Whyte predicts that discourse domains will affect learners' spoken discourse in interviews with her: Learners will construct oral texts on discourse domain topics that are more complex, more independent, and more coherent than when they speak on general topics. She measures these features by means of both turn-taking patterns and episode structure, but finds only limited support for the DD hypothesis. The lack of a strong relationship between DD and learners' speech may be because it is hard to identify domain topics in advance of interaction since some speakers are not invested in their academic major or the topic of the paper they have written in class. A further reason may be that the experimental and control subjects were matched for age and ESL proficiency but not for L1 background. As Young (1995) and Young and Halleck (1998) have found, the L1 background of speakers can make a big difference in the type of discourse produced in interviews. Whyte's study is an interesting example of the problems involved in defining "context" in advance of interaction.

\section{UNANNOTATED BIBLIOGRAPHY}

Adamson, H. D., B. Fonseca-Greber, K. Kataoka, V. Scardino and S. Takano. 1996. Tense marking in the English of Spanish-speaking adolescents. In R. Bayley and D. R. Preston (eds.) Second language acquisition and linguistic variation. Philadelphia: John Benjamins. 121-134.

Agar, M. 1994. Language shock: Understanding the culture of conversation. New York: Morrow.

Aukrust, V. G. and C. E. Snow. 1998. Narratives and explanations during mealtime conversations in Norway and the U.S. Language in Society. 27.221-246.

Bachman, L. F. 1990. Fundamental considerations in language testing. New York: Oxford University Press.

Bateson, G. 1972. Steps to an ecology of mind. New York: Ballantine.

Bayley, R. 1994. Interlanguage variation and the quantitative paradigm: Past tense marking in Chinese-English. In E. E. Tarone, S. M. Gass and A. D. Cohen (eds.) Research methodology in second-language acquisition. Hillsdale, NJ: L. Erlbaum. 157-181.

1996. Competing constraints on variation in the speech of adult Chinese learners of English. In R. Bayley and D. R. Preston (eds.) Second language acquisition and linguistic variation. Philadelphia: John Benjamins. 97-120. 
Berry, A. 1994. Spanish and American turn-taking styles: A comparative study. Pragmatics and Language Learning Monograph Series. Volume 5. 180-190.

Bourdieu, P. 1991. Language and symbolic power. Cambridge, MA: Harvard University Press.

Braidi, S. M. 1995. Reconsidering the role of interaction and input in second language acquisition. Language Learning. 45.141-175.

Bremer, K., C. Roberts, M. Vassear, M. Simonot and P. Broder. 1996. Achieving understanding: Discourse in intercultural encounters. London: Longman.

Cameron, R. and J. Williams. 1997. Senténce to ten cents: A case study of relevance and communicative success in nonnative-native speaker interactions in a medical setting. Applied Linguistics. 18.415-445.

Canale, M. and M. Swain. 1980. Theoretical bases of communicative approaches to second language teaching and testing. Applied Linguistics. 1.1-47.

Cazden, C. B. 1988. Classroom discourse: The language of teaching and learning. Portsmouth, NH: Heinemann.

Clancy, P. M. 1986. The acquisition of communicative style in Japanese. In B. B. Schieffelin and E. Ochs (eds.) Language socialization across cultures. New York: Cambridge University Press. 213-250.

Davidson, C. N. 1993. 36 views of Mount Fuji: On finding myself in Japan. New York: Dutton.

Douglas, D. and L. Selinker. 1985. Principles for language tests within the 'discourse domains' theory of interlanguage: Research, test construction and interpretation. Language Testing. 2.205-226.

1992. Analyzing oral proficiency test performance in general and specific purpose contexts. System. 20.317-328.

1993. Performance on a general versus a fieldspecific test of speaking proficiency by international teaching assistants. In D. Douglas and C. Chapelle (eds.) A new decade of language testing research: Selected papers from the 1990 Language Testing Research Colloquium. Alexandria, VA: Teachers of English to Speakers of Other Languages. 235-256.

Douglas, D. and L. Selinker. 1994a. Native and nonnative teaching assistants: A case study of discourse domains and genres. In C. G. Madden and C. L. Myers (eds.) Discourse and performance of international teaching assistants. Alexandria, VA: Teachers of English to Speakers of Other Languages. 221-230.

1994b. Research methodology in context-based second-language research. In E. E. Tarone, S. M. Gass and A. D. Cohen (eds.) Research methodology in second-language acquisition. Hillsdale, NJ: L. Erlbaum. 119-131.

Ebsworth, T. and M. E. Ebsworth. 1997. Island Puerto Rican and continental American responses to critical incidents: An intercultural study of language, norms, and values. Research on Language and Social Interaction. 30.193-233. 
Eckman, F. R. 1994. The competence-performance issue in second-language acquisition theory: A debate. In E. E. Tarone, S. M. Gass and A. D. Cohen (eds.) Research methodology in second-language acquisition. Hillsdale, NJ: L. Erlbaum. 3-15.

Ehrlich, S. 1997. Gender as social practice: Implications for second language acquisition. Studies in Second Language Acquisition. 19.421-446.

Ehrman, M. E. 1996. Understanding second language learning difficulties. Thousand Oaks, CA: Sage.

Ellis, R. 1985. Sources of variability in interlanguage. Applied Linguistics. 6.118-131.

1989. Sources of intra-learner variability in language use and their relationship to second language acquisition. In S. Gass, C. Madden, D. R. Preston and L. Selinker (eds.) Variation in second language acquisition, Volume II: Psycholinguistic issues. Clevedon, Avon: Multilingual Matters. 22-45.

1990. A response to Gregg. Applied Linguistics. 11.384-391.

Ferguson, C. A. 1997. History of sociolinguistics: Interview with Charles Ferguson. In C. B. Paulston and G. R. Tucker (eds.) The early days of sociolinguistics: Memories and reflections. Dallas, TX: Summer Institute of Linguistics. 77-95.

Firth, A. and J. Wagner. 1997. On discourse, communication, and (some) fundamental concepts in SLA. Modern Language Journal. 81.285-300.

Freed, A. F. 1996. Language and gender research in an experimental setting. In V. L. Bergvall, J. M. Bing and A. F. Freed (eds.) Rethinking language and gender research: Theory and practice. London: Longman. 54-76. and A. Greenwood. 1996. Women, men, and type of talk; What makes the difference? Language in Society. 25.1-26.

Gallego, J. C. 1997. Language- vs. content-related trouble in understanding:

NNSTAs at office hours. Pragmatics and Language Learning Monograph Series. Volume 8. 179-200.

Gardner, R. 1998. Between speaking and listening: The vocalisation of understandings. Applied Linguistics. 19.204-224.

Goffman, E. 1956. The nature of deference and demeanor. American Anthropologist. 58.473-502.

1963. Stigma: Notes on the management of spoiled identity. New York: Simon and Schuster.

1981. Forms of talk. Philadelphia: University of Pennsylvania Press.

Goldstein, T. 1997. Two languages at work: Bilingual life on the production floor. New York: Mouton de Gruyter.

Gómez-Peña, G. 1993. Warrior for gringostroika. St. Paul, MN: Graywolf Press. 1996. The new world border: Prophecies, poems \& loqueras for the end of the century. San Francisco, CA: City Lights.

Goodwin, C. and A. Duranti. 1992. Rethinking context: An introduction. In A. Duranti and C. Goodwin (eds.) Rethinking context: Language as an interactive phenomenon. New York: Cambridge University Press. 1-42. 
Gregg, K. R. 1990. The variable competence model of second language acquisition and why it isn't. Applied Linguistics. 11.364-383.

Griffin, P. and M. Cole. 1984. Current activity for the future: The ZOPED. In B. Rogoff and J. Wertsch (eds.) Children's learning in the zone of proximal development. San Francisco, CA: Jossey Bass. 45-63.

Gumperz, J. J. 1990. The conversational analysis of interethnic communication. In R. C. Scarcella, E. S. Anderson and S. D. Krashen (eds.) Developing communicative competence in a second language. New York: Newbury House. 223-238.

1992. Contextualization and understanding. In A. Duranti and C. Goodwin (eds.) Rethinking context: Language as an interactive phenomenon. New York: Cambridge University Press. 229-252.

and C. Roberts. 1991. Understanding in intercultural encounters. In

J. Blommaert and J. Verschueren (eds.) The pragmatics of intercultural and international communication. Philadelphia: John Benjamins. 51-89.

Günthner, S. 1996. Male-female speaking practices across cultures. In M. Hellinger and U. Ammon (eds.) Contrastive sociolinguistics. New York: Mouton de Gruyter. 447-473.

Hall, J. K. 1993. The role of oral practices in the accomplishment of our everyday lives: The sociocultural dimension of interaction with implications for the learning of another language. Applied Linguistics. 14.145-166.

1995. (Re)creating our worlds with words: A sociohistorical perspective of face-to-face interaction. Applied Linguistics. 16.206-232.

Hall, S. 1992. The question of cultural identity. In S. Hall, D. Held and T. McGrew (eds.) Modernity and its futures. Cambridge: Polity Press in association with the Open University. 274-316.

Halliday, M. A. K. 1978. Language as social semiotic: The social interpretation of language and meaning. London: Edward Arnold.

He, A. W. and R. Young. 1998. Language proficiency interviews: A discourse approach. In R. Young and A. W. He (eds.) Talking and testing: Discourse approaches to the assessment of oral proficiency. Philadelphia: John Benjamins. 1-24.

Hinkel, E. 1994. Topic appropriateness in cross-cultural social conversations. Pragmatics and Language Learning Monograph Series. Volume 5. 163-179.

Hoffman, E. 1989. Lost in translation: A life in a new language. New York: Penguin Books.

Hymes, D. 1972. On communicative competence. In J. B. Pride and J. Holmes (eds.) Sociolinguistics: Selected readings. Harmondsworth, Middlesex: Penguin. 269-293.

1974. Foundations in sociolinguistics: An ethnographic approach. Philadelphia: University of Pennsylvania Press.

Jacoby, S. and E. Ochs. 1995. Co-construction: An introduction. Research on Language and Social Interaction. 28.171-183.

Kaplan, A. 1993. French lessons: A memoir. Chicago: University of Chicago Press. 
Kasper, G. 1997. Beyond reference. In G. Kasper \& E. Kellerman (eds.) Communication strategies: Psycholinguistic and sociolinguistic perspectives. London: Longman. 345-360.

Kim, K.-h. and K.-h. Suh. 1998. Confirmation sequences as interactional resources in Korean language proficiency interviews. In R. Young and A. W. He (eds.) Talking and testing: Discourse approaches to the assessment of oral proficiency. Philadelphia: John Benjamins. 297-332.

Kramsch, C. 1986. From language proficiency to interactional competence. Modern Language Journal. 70.366-372.

Le Page, R. B. and A. Tabouret-Keller. 1985. Acts of identity: Creole-based approaches to language and ethnicity. New York: Cambridge University Press.

Leung, C., R. Harris and B. Rampton. 1995. The idealised native speaker, reified ethnicities, and classroom realities. TESOL Quarterly. 31.543-560.

Liberman, K. 1995. The natural history of some intercultural communication. Research on Language and Social Interaction. 28.117-146.

Liu, G.-q. 1991.Interaction and second language acquisition: A case study of a Chinese child's acquisition of English. Bundoora, Victoria, Australia: La Trobe University. Ph.D. diss.

Liu, Z. 1984. Two years in the melting pot. San Francisco, CA: China Books.

Losey, K. M. 1995. Gender and ethnicity as factors in the development of verbal skills in bilingual Mexican American women. TESOL Quarterly. 29.635-661.

1997. Listen to the silences: Mexican American interaction in the composition classroom and community. Norwood, NJ: Ablex.

Markee, N. P. 1994. Toward an ethnomethodological respecification of secondlanguage acquisition studies. In E. E. Tarone, S. M. Gass and A. Cohen (eds.) Research methodology in second-language acquisition. Hillsdale, NJ: L. Erlbaum. 89-116.

McGroarty, M. 1998. Constructive and constructivist challenges for applied linguistics. Language Learning. 48.591-622.

McKay, S. L. and N. H. Hornberger (eds.) 1996. Sociolinguistics and language teaching. New York: Cambridge University Press.

McNamara, T. F. 1997b. What do we mean by social identity? Competing frameworks, competing discourses. TESOL Quarterly. 31.561-567.

Meeuwis, M. 1994. Leniency and testiness in intercultural communication: Remarks on ideology and context in interactional sociolinguistics. Pragmatics. 4.391-408.

Mora, R. 1995. Silence, interruptions, and discourse domains: The opportunities to speak. Applied Language Learning. 6.27-39.

Mori, K. 1997. Polite lies: On being a woman caught between cultures. New York: Henry Holt.

Ochs, E. and B. B. Schieffelin. 1979. Developmental pragmatics. New York: Academic Press. 
Paikeday, T. M. 1985. The native speaker is dead! An informal discussion of linguistic myth with Noam Chomsky and other linguists, philosophers, psychologists, and lexicographers. Toronto: Paikeday Publishing.

Peirce, B. N. 1995. Social identity, investment, and language learning. TESOL Quarterly. 29.9-31.

Pica, T. 1994. Research on negotiation: What does it reveal about second-language learning conditions, processes, and outcomes? Language Learning. 44.493-527.

Pickett, G. D. 1978. The foreign language learning process. London: The British Council English Teaching Information Centre.

Pienemann, M. and M. Johnston. 1987. Factors influencing the development of language proficiency. In D. Nunan (ed.) Applying second language acquisition research: Adelaide, Australia: National Curriculum Resource Centre. 45-141.

Preston, D. R. 1996. Variationist perspectives on second language acquisition. In R. Bayley and D. R. Preston (eds.) Second language acquisition and linguistic variation. Philadelphia: John Benjamins. 1-45.

Psathas, G. (ed.) 1989. Interaction competence. Lanham, MD: University Press of America.

Rampton, B. 1997. A sociolinguistic perspective on L2 communication strategies. In G. Kasper and E. Kellerman (eds.) Communication strategies: Psycholinguistic and sociolinguistic perspectives. London: Longman. 279-303.

Ranney, S. 1992. Learning a new script: An exploration of sociolinguistic competence. Applied Linguistics. 13.25-50.

Regan, V. 1996. Variation in French interlanguage: A longitudinal study of sociolinguistic competence. In R. Bayley and D. R. Preston (eds.) Second language acquisition and linguistic variation. Philadelphia: John Benjamins. 177-201.

Rodriguez, R. 1982. Hunger of memory: The education of Richard Rodriguez. New York: Bantam.

Rogoff, B. 1990. Apprenticeship in thinking: Cognitive development in social context. New York: Oxford University Press.

Rommetveit, R. 1985. Language acquisition as increasing linguistic structuring of experience and symbolic behavior control. In J. V. Wertsch (ed.) Culture, communication, and cognition: Vygotskian perspectives. New York: Cambridge University Press. 183-204. 1987. Meaning, context, and control. Inquiry. 30.77-99.

Ross, S. 1998. Divergent frame interpretations in language proficiency interview interaction. In R. Young and A. W. He (eds.) Talking and testing: Discourse approaches to the assessment of oral proficiency. Philadelphia: John Benjamins. 333-353.

Sarangi, S. 1994. Intercultural or not? Beyond celebration of cultural differences in miscommunication analysis. Pragmatics. 4.409-427. 
Schechter, S. R. and R. Bayley. 1997. Language socialization practices and cultural identity: Case studies of Mexican-descent families in California and Texas. TESOL Quarterly. 31.513-541.

Schegloff, E. A. 1987. Between macro and micro: Contexts and other connections. In J. C. Alexander, B. Giesen, R. Münch and N. J. Smelser (eds.) The micro-macro link. Berkeley: University of California Press. 207-234.

1993. Reflection on quantification in the study of conversation. Research on Language and Social Interaction. 26.99-128.

Schieffelin, B. B. and E. Ochs (eds.) 1986. Language socialization across cultures. New York: Cambridge University Press.

Schumann, J. H. 1997. The neurobiology of affect in language. Malden, MA: Blackwell.

Scollon, R. and S. W. Scollon. 1995. Intercultural communication: A discourse approach. Cambridge, MA: Blackwell.

Selinker, L. and D. Douglas. 1985. Wrestling with 'context' in interlanguage theory. Applied Linguistics. 6.190-204.

1989. Research methodology in contextually-based second language research. Second Language Research. 5.93-126.

Singh, R., J. Lele and G. Martohardjono. 1988. Communication in a multilingual society: Some missed opportunities. Language in Society. 17.43-59.

Sperber, D. and D. Wilson. 1995. Relevance: Communication and cognition. Cambridge, MA: Blackwell.

Stevick, E. W. 1989. Success with foreign languages: Seven who achieved it and what worked for them. New York: Prentice Hall.

Swain, M. 1985. Communicative competence: Some roles of comprehensible input and comprehensible output in its development. In S. M. Gass and C. G. Madden (eds.) Input in second language acquisition. Rowley, MA: Newbury House. 235-253.

Tajfel, H. 1981. Human groups and social categories: Studies in social psychology. New York: Cambridge University Press.

Tarone, E. 1990. On variation in interlanguage: A response to Gregg. Applied Linguistics. 11.392-400.

In press. A sociolinguistic perspective on an SLA theory of mind. Studia Anglica Posnaniensa.

Tarone, E. and M. Swain. 1995. A sociolinguistic perspective on second-language use in immersion classrooms. Modern Language Journal. 79.166-178.

van Betteraij, M. and E. Kellerman. 1996. Self-disclosure and safe topics of conversation: A cross-cultural appraisal. In E. Kellerman, B. Weltens and T. Bongaerts (eds.) EUROSLA 6: A selection of papers. Amsterdam: Vrije Universiteit Uitgeverij. 35-46.

Vygotsky, L. S. 1978. Mind in society: The development of higher psychological processes. Cambridge, MA: Harvard University Press.

Wagner, J. and A. Firth. 1997. Communication strategies at work. In G. Kasper and E. Kellerman (eds.) Communication strategies: Psycholinguistic and sociolinguistic perspectives. London: Longman. 323-344. 
Watson, R. 1995. The philosopher's demise: Learning French. Columbia, MO: University of Missouri Press.

Weedon, C. 1997. Feminist practice and poststructuralist theory. 2nd ed. Malden, MA: Blackwell.

Weinreich, U., W. Labov and M. I. Herzog. 1968. Empirical foundations for a theory of language change. In W. P. Lehmann and Y. Malkiel (eds.) Directions for historical linguistics: A symposium. Austin, TX: University of Texas Press. 97-105.

Whyte, S. 1994a. Acquisition in context: The discourse domain hypothesis of interlanguage variation. Pragmatics and Language Learning Monograph Series. Volume 5. 289-315.

1994b. The role of specialized knowledge in interlanguage variation: The discourse domain hypothesis. Bloomington, IN: Indiana University. Ph.D. diss.

Williams, J., R. Inscoe and T. Tasker. 1997. Communication strategies in an interactional context: The mutual achievement of comprehension. In $\mathrm{G}$. Kasper and E. Kellerman (eds.) Communication strategies:

Psycholinguistic and sociolinguistic perspectives. London: Longman. 304-322.

Young, R. 1995. Conversational styles in language proficiency interviews. Language Learning. 45.3-42.

1996. Form-function relations in articles in English interlanguage. In R. Bayley and D. R. Preston (eds.) Second language acquisition and linguistic variation. Philadelphia: John Benjamins. 135-175.

and R. Bayley. 1996. VARBRUL analysis for second language acquisition research. In R. Bayley and D. R. Preston (eds.) Second language acquisition and linguistic variation. Philadelphia: John Benjamins. 253-306.

and G. B. Halleck. 1998. "Let them eat cake!" or how to avoid losing your head in cross-cultural conversations. In R. Young and A. W. He (eds.) Talking and testing: Discourse approaches to the assessment of oral proficiency. Philadelphia: John Benjamins. 355-382.

and A. W. He. (eds.) 1998. Talking and testing: Discourse approaches to the assessment of oral proficiency. Philadelphia: John Benjamins.

Zentella, A. C. 1997. Growing up bilingual: Puerto Rican children in New York. Malden, MA: Blackwell.

Zuengler, J. 1989. Performance variation in NS-NNS interactions: Ethnolinguistic difference, or discourse domain? In S. Gass, C. Madden, D. R. Preston and L. Selinker (eds.) Variation in second language acquisition, Volume I: Discourse and pragmatics. Clevedon, Avon: Multilingual Matters. 228-244.

and B. Bent. 1991. Relative knowledge of content domain: An influence on native-non-native conversations. Applied Linguistics. 12.397-415. 